\title{
Clinical, endoscopic and pathological characteristics of colorectal polyps in elderly patients: Single-center experience
}

\author{
LEI ZHOU, HENG ZHANG, SHENGBIN SUN, MANLING HUANG, JING LIU, DAN XU, MIN SONG, \\ CHENMING SUN, HUI LI, DAN ZHENG, YAN FAN, YUSHENG LIAO, PING WANG and JIE WU
}

\begin{abstract}
Department of Gastroenterology and Key Laboratory for Molecular Diagnosis of Hubei, The Central Hospital of Wuhan, Tongji Medical College, Huazhong University of Science and Technology, Wuhan, Hubei 430014, P.R. China
\end{abstract}

Received July 25, 2016; Accepted March 23, 2017

DOI: $10.3892 /$ mco.2017.1284

\begin{abstract}
Increasing age is a risk factor for the development of colorectal adenomas and advanced adenomas. However, few studies have been published on the features of colorectal polyps in the elderly. The present study aimed to investigate the clinical, enteroscopic and pathological characteristics of colorectal polyps in Chinese elderly patients in a single center (The Central Hospital of Wuhan, Hubei, China). The endoscopic and pathological reports of colonoscopies performed in our center were retrospectively analyzed. A total of 7,795 consecutive patients referred for colonoscopy were evaluated between January 2013 and December 2014. Of the 297 who met the inclusion criteria, 279 polyps were observed in men and 230 in women. Of all the polyps, 263 were non-adenomatous polyps, 104 were non-advanced adenomas and 142 were advanced adenomas. 336 polyps were left-sided and 173 were right-sided. Polyps $\geq 10 \mathrm{~mm}$ were more likely to exhibit an adenomatous component and advanced features, and these findings continued to hold true when the size cut-off was set at $5 \mathrm{~mm}$. The data shown in the present study have revealed that a significant number of polyps lie proximal to the splenic flexure. Thus, evaluation of the whole bowel is particularly important in elderly patients who are undergoing colonoscopy. In addition, the polyp size was associated with the presence of adenoma, and advanced component, diminutive and small polyps should not be ignored in elderly patients.
\end{abstract}

\section{Introduction}

Colorectal cancer (CRC) is the third most commonly diagnosed cancer in males and the second most commonly diagnosed

Correspondence to: Professor Jie Wu, Department of Gastroenterology and Key Laboratory for Molecular Diagnosis of Hubei, The Central Hospital of Wuhan, Tongji Medical College, Huazhong University of Science and Technology, 26 Shengli Street, Wuhan, Hubei 430014, P.R. China

E-mail:wujie12375@126.com

Key words: colorectal polyps, colonoscopy, elderly cancer in females, with over 1.3 million new cancer cases, and 693,900 mortalities, estimated to have occurred in 2012 (1). China, similarly to several other developing countries in Asia, has been experiencing a significant rise in the incidence of CRC over the recent decades (2-4).

It is widely accepted that the adenoma-carcinoma sequence represents the process by which most cases of CRC arise (5). Several studies have revealed that age is one of the most important influential factors for colorectal adenoma: An older age ( $\geq 65$ years) is associated with a higher prevalence of adenoma and advanced adenoma (6,7). In addition, the prevalence of adenoma and advanced adenoma in persons 76-80 years of age is more than double that of persons aged 40-49 years (8). The comparatively high rate of incidence of adenomatous and advanced adenomatous polyps in the older population makes this group an important CRC screening target.

Features of polyps in the colorectum may affect the selection of screening and surveillance modalities for CRC (9). However, few studies have been published on the features of colorectal polyps in elderly. Therefore, the aim of the present study was to investigate the clinical, enteroscopic and pathological characteristics of colorectal polyps in Chinese elderly patients in a single center (The Central Hospital of Wuhan, Hubei, China).

\section{Patients and methods}

Study design and patients. The present retrospective study was based on the colonoscopic database information from all colonoscopic examinations performed at the Central Hospital of Wuhan, Hubei, China between January 2013 and December 2014. The study protocol was reviewed and approved by the Ethics and Research Committee of the Central Hospital of Wuhan.

For the analysis of the features of colorectal polyps in elderly patients, the following inclusion criteria were used: (1) the patient was $\geq 65$ years of age; (2) the patient had received an endoscopic resection of colorectal polyps; (3) complete medical records were available. Exclusion criteria were as follows: i) the patient was $<65$ years; ii) there was an absence of polyps; iii) the polyps were unresected (due to taking anticoagulant drugs, multiple comorbid conditions, income inadequacy or low social support), or the polyps were observed, but not 
retrieved (by reason of small, sessile, and proximal colon polyps); iv) the patients were suffering from melanosis coli, colorectal cancer, inflammatory bowel disease, active gastrointestinal bleeding or familial adenomatous polyposis; v) there was a history of colectomy or rectectomy; vi) the colonoscopy did not reach the cecum; and vii) the bowel preparation was poor (semi-solid stool that could not be suctioned or washed away, and $<90 \%$ of mucosal visualization) (10).

Procedures and definitions. Procedures were performed by 14 colonoscopists: Seven experienced colonoscopists, each of whom had performed in excess of 2,000 colonoscopies and had been in colonoscopy practice for $>10$ years, and seven less experienced colonoscopists, who had had 3-5 years of colonoscopy practice, during which each had performed between 300 and 500 colonoscopies. Our center used polyethylene glycol-electrolyte powder (PEG-ELP; WanHe Pharmaceutical Co., Ltd., Shenzhen, China) as a purgative for all patients who underwent a colonoscopy. Colonoscopies were performed following bowel preparation with 31 PEG-ELP.

The colonoscopes used in the present study [an OLYMPUS GIF-XQ240 (Pro Scope Systems, Blue Ash, OH, USA) and a PENTAX EC-3890Fi (PENTAX Medical Co., Montvale, NJ, USA)] are both utilized in standard electronic colonoscopies. Additional technologies, including narrow band imaging and i-Scan, were not regularly used. Polypectomies were performed using standard biopsy forceps (for polyps $<5 \mathrm{~mm}$ ) or polypectomy snares for larger polyps ( $>5 \mathrm{~mm}$ ). Polyp size was estimated by comparing a polyp to the fully opened biopsy forceps (7 mm in length; JHY-FB-23-180-O-O; Changzhou Jiuhong Medical Instrument Co., Ltd., Changzhou, China) or polypectomy snares (15 mm in diameter; NOE342214-C; Endo-Flex GmbH, Voerde, Germany).

Precise characteristics of the colorectal polyps (i.e., number, size, form, and location) were documented in the colonoscopy reports by endoscopists.

Following polypectomy, the samples were sent to the pathology department of the Central Hospital of Wuhan, and processed for routine histological examination. Two experienced gastrointestinal pathologists evaluated the histopathology of the samples, and entered details of the histological features of polyps in the pathology reports.

All the demographic data, including the age and sex of the patients and information regarding the colorectal polyps, were collected from the endoscopy and pathology databases of our center. The indications for colonoscopy were reviewed manually from the medical files.

For the purpose of the present analysis, colorectal polyps were divided into two groups: The right-sided and left-sided lesions. Polyps located proximal to the splenic flexure were considered right-sided (including the cecum, ascending colon and transverse colon), whereas those that were distal to the splenic flexure were considered left-sided (including the descending colon, sigmoid colon and rectum).

In the present study, colorectal polyps were divided into two types based on their histological findings: Non-adenomatous polyps (NAPs; benign mucosa, inflammatory, hyperplasic, lymphoid, lipomatous, and so forth) and adenomatous polyps (APs; tubular, villous, tubulovillous, and serrated adenoma). APs were further grouped as non-advanced adenomas (NAAs) and advanced adenomas (AAs). AAs were those possessing the following features: $\geq 10 \mathrm{~mm}$ in diameter, having villous or tubulovillous histology, having high-grade dysplasia (HGD), or any combination of these features (11).

The morphology of the colorectal polyps was determined according to the Paris classification, being classified into protruding lesions [elevated by $>2.5 \mathrm{~mm}$ above the mucosal layer: Pedunculated (0-Ip), sessile ( 0 -Is) or semipedunculated (0-Isp)], superficial lesions [slightly elevated by $<2.5 \mathrm{~mm}$ (0-IIa), flat (0-IIb) or slightly depressed (0-IIc)], and laterally spreading tumors (LSTs) (12). The colorectal polyps were classified according to their size as follows: $\leq 5 \mathrm{~mm}, 6-9 \mathrm{~mm}$, $10-20 \mathrm{~mm}$ and $>20 \mathrm{~mm}$.

Statistical analysis. All statistical analyses were performed using SPSS version 17.0 software (SPSS, Inc., Chicago, IL, USA) and GraphPad Prism version 5.0 (GraphPad Software Inc., San Diego, CA, USA). Fisher's exact test was used for between-group comparisons. $\mathrm{P}<0.05$ was considered to indicate a statistically significant difference.

\section{Results}

Between January 2013 and December 2014, a total of 7,795 consecutive patients undergoing colonoscopy at our center (The Central Hospital of Wuhan, Hubei, China) were retrospectively analyzed. A total of 7,498 patients were excluded who met the exclusion criteria, and therefore 297 patients were included in the present study (Fig. 1). The general characteristics of these patients are summarized in Table I. The mean age was $71.4 \pm 5.2$ years (range, $65-87$ years); $149(50.2 \%)$ of the patients were male and $148(49.8 \%)$ were female, and 161 patients $(54.2 \%)$ were aged 70 years or older.

The indications for colonoscopy examination included a change in bowel habit $(24.2 \%)$, abdominal pain $(19.5 \%)$, constipation $(14.1 \%)$, rectal bleeding or hematochezia $(10.1 \%)$, positive fecal occult blood $(7.4 \%)$, regular health examination (7.1\%), diarrhea (6.7\%), abdominal distention (5.4\%), and other less common indications, including melena, anus bulge, weight loss, anemia, an abdominal mass or anus fistula (Table II).

Altogether, a total of 509 colorectal polyps were resected from 297 patients. The histological findings are shown in Table III. Of all polyps, $263(51.7 \%)$ were NAPs and 246 $(48.3 \%)$ were APs. Of all the NAPs, 227 (44.6\%) were inflammatory polyps, $24(4.7 \%)$ were hyperplastic polyps, $6(1.2 \%)$ were normal mucosa and $6(1.2 \%)$ were others. Of all the APs, $104(20.4 \%)$ were NAAs, and 142 (27.9\%) were AAs. The histological finding of NAAs was tubular adenoma. The 142 AAs comprised 11 (2.2\%) tubular adenomas, 14 (2.7\%) villous adenomas, 115 (22.6\%) tubulovillous adenomas and $2(0.4 \%)$ serrated adenomas. Among the AAs, 9 (1.8\%) polyps were noted to have HGD.

In men, 279 (54.8\%) polyps were noted, of which 150 (29.5\%) were NAPs, $52(10.2 \%)$ were NAAs and $77(15.1 \%)$ were AAs. In women, 230 (45.2\%) polyps were noted, of which $113(22.2 \%)$ were NAPs, 52 (10.2\%) were NAAs and 65 $(12.8 \%)$ were AAs. The number of colorectal polyps according to sex is shown in Fig. 2A. No association was identified between sex and the histological finding of colorectal polyps (P>0.05; Fig. 2A). 


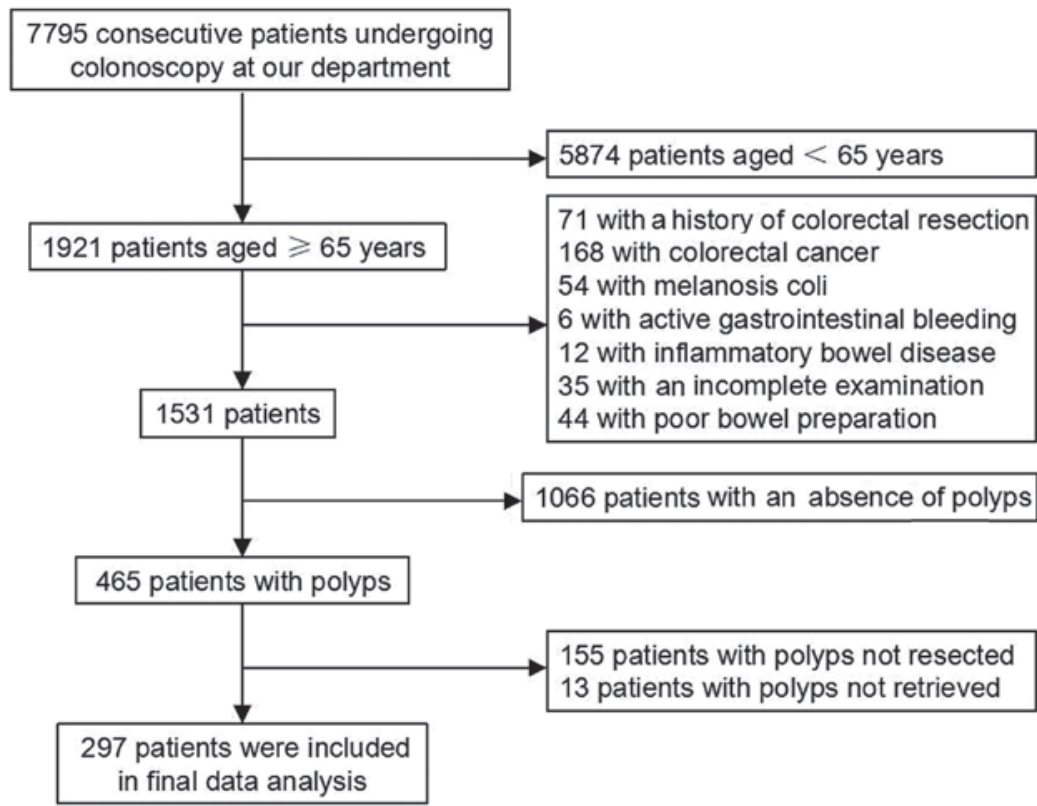

Figure 1. Flow diagram of the present study.

Of all the polyps, 242 (47.5\%), 141 (27.7\%), 84 (16.5\%) and $42(8.3 \%)$ were identified in patients of 65-69, 70-74, 75-79, and $\geq 80$ years of age, respectively. A comparison of the polyps according to age, using 75 years as a cut-off, revealed that $36.5 \%(46 / 126)$ of the polyps in patients $\geq 75$ years of age had an advanced feature compared with $25.1 \%$ (96/383) of those in patients aged 65-74 years $(\mathrm{P}<0.05$; Fig. $2 \mathrm{~B}$ and Table IV), although there were no between-group differences in the frequency of NAPs and APs (P>0.05; Fig. $2 \mathrm{~B}$ and Table IV).

In the right-sided colon, $173(34.0 \%)$ polyps were identified, of which $91(17.9 \%)$ were NAPs, 39 (7.7\%) were NAAs and $43(8.4 \%)$ were AAs. In the left-sided colon, $336(66.0 \%)$ polyps were identified, of which $172(33.8 \%)$ were NAPs, 65 (12.8\%) were NAAs and 99 (19.4\%) were AAs. The number of colorectal polyps according to distribution is shown in Fig. 3. There was no association between distribution and the histological findings of colorectal polyps ( $\mathrm{P}>0.05$; Fig. 3A). It is worth noting that the sigmoid colon was the most frequent site for the three different types of polyps, and the rectum, ascending colon and rectum were the second most frequent site for NAPs, NAAs, and AAs, respectively (Fig. 3B).

In terms of morphology, the colorectal polyps could be classified as follows: $27(5.3 \%)$ were type 0-Ip, $49(9.6 \%)$ were type 0 -Isp, $327(64.2 \%)$ were type 0 -Is, 96 (18.9\%) were type 0 -IIa, and $10(2.0 \%)$ were LSTs. No completely flat or depressed lesions (type 0 -IIb or 0 -IIc) were noted. The morphological appearance of polyps according to the Paris classification is shown in Fig. 4A. It was identified that the sessile type (0-Is) appeared the most frequently for the three different histological features of polyps (Fig. 4A).

Regarding the polyps' size, $330(64.8 \%)$ were $\leq 5 \mathrm{~mm}$ in terms of their greatest dimension, $108(21.2 \%)$ were $6-9 \mathrm{~mm}$, $60(11.8 \%)$ were $10-20 \mathrm{~mm}$, and $11(2.2 \%)$ were $>20 \mathrm{~mm}$. The size of the polyps according to the histopathological findings is described in Fig. 4B. A comparison of polyps by size, using $10 \mathrm{~mm}$ as a cut-off, revealed that larger polyps were more likely to exhibit an adenomatous component, and tended to be advanced.
Approximately $40.9 \%$ (179/438) of the polyps $<10 \mathrm{~mm}$ in size had an adenomatous component, compared with $94.4 \%$ (67/71) of those $\geq 10 \mathrm{~mm}(\mathrm{P}<0.0001$; Fig. $4 \mathrm{~B}$ and Table $\mathrm{V})$. In addition, only $17.1 \%(75 / 438)$ of the polyps that were $<10 \mathrm{~mm}$ in size had an advanced feature, compared with $94.4 \%$ (67/71) of those $\geq 10 \mathrm{~mm}(\mathrm{P}<0.0001$; Fig. $4 \mathrm{~B}$ and Table V). Similar findings were also observed when the size cut-off was set at $5 \mathrm{~mm}$. Only $33.0 \%(109 / 330)$ of the polyps $\leq 5 \mathrm{~mm}$ in size had an adenomatous component, compared with 76.5\% (137/179) of those $6 \mathrm{~mm}$ or larger $(\mathrm{P}<0.0001$; Fig. 4B and Table V). Furthermore, only $14.8 \%$ (49/330) of the polyps $\leq 5 \mathrm{~mm}$ in size had an advanced feature, compared with $52.0 \%$ (93/179) of those $6 \mathrm{~mm}$ or larger $(\mathrm{P}<0.0001$; Fig. 4B and Table V).

\section{Discussion}

The present study has retrospectively analyzed the clinical, endoscopic and pathological characteristics of colorectal polyps in Chinese elderly patients over a period of two years through the analysis of endoscopic and pathology reports in a single center (The Central Hospital of Wuhan, Hubei, China).

In the present study, it was observed that there were no specific clinical symptoms in older patients with colorectal polyps, and the majority of patients presented with changes in bowel habit or other symptoms, including abdominal pain, constipation, rectal bleeding or hematochezia, and positive fecal occult blood, which was similar to findings reported in other retrospective studies $(13,14)$.

An advancing age is an independent risk factor for developing colorectal adenomas, which may lead to higher rates of colorectal cancer in the elderly (7). In one study, the prevalence of colorectal adenomas increased markedly with age among participants aged 20-79 years, although the increase was more marked for AAs (15). In the present study, the AAs were more common in patients $\geq 75$ years of age, compared with patients who were 65-74 years of age, but the incidence of APs was 
Table I. General characteristics of the elderly patients studied.

\begin{tabular}{lc}
\hline Characteristic & Results \\
\hline Number of patients & 297 \\
Sex & \\
Male & 149 \\
Female & 148 \\
Age (years) & \\
65-69 & 136 \\
$70-74$ & 83 \\
$75-79$ & 51 \\
$\geq 80$ & 27 \\
Age range (years) & $65-87$ \\
Mean age (years) & $71.4 \pm 5.2^{\mathrm{a}}$ \\
\hline
\end{tabular}

${ }^{a}$ Data are shown as the mean \pm standard deviation of the mean.

Table II. Indications for colonoscopy examinations.

\begin{tabular}{lc}
\hline Indication & Number of patients \\
\hline Rectal bleeding or hematochezia & 30 \\
Positive fecal occult blood & 22 \\
Constipation & 42 \\
Diarrhea & 20 \\
Abdominal pain & 58 \\
Abdominal distention & 16 \\
Change in bowel habit & 72 \\
Melena & 6 \\
Anus bulge & 3 \\
Weight loss & 3 \\
Anemia & 2 \\
Abdominal mass & 1 \\
Anus fistula & 1 \\
Regular health examination & 21 \\
Total & 297 \\
\hline
\end{tabular}

not significantly associated with age, perhaps due to a more selective and smaller sample size, or other biases.

Data published in recent studies have revealed that males had a greater likelihood of developing a larger number of APs and AAs compared with females $(15,16)$, whereas in the present study, no significant differences were observed between the sexes. The findings of the present study are similar to those reported in a previous study by Yamaji et al (17), who reported that sex was not to be considered as an independent risk factor for the development of advanced colorectal adenomas (17). This may be due to the small sample size in the present study, or an increasing risk in women as they grow older.

The present study has shown that left-sided colorectal polyps were more prevalent than right-sided ones, a finding that is in agreement with previous studies $(18,19)$. In the present study, APs and AAs were detected predominantly in
Table III. Histopathological features of the 509 colorectal polyps.

\begin{tabular}{lc}
\hline Histopathology of resected polyps & Result $(\%)$ \\
\hline Non-adenomatous polyps & $263(51.7)$ \\
Inflammatory polyp & $227(44.6)$ \\
Hyperplastic polyp & $24(4.7)$ \\
Normal mucosa & $6(1.2)$ \\
Other & $6(1.2)$ \\
Adenomatous polyps & $246(48.3)$ \\
Non-advanced adenomas & $104(20.4)$ \\
Tubular adenoma & \\
Size $<10$ mm with LGD & $104(20.4)$ \\
Advanced adenomas & $142(27.9)$ \\
Tubular adenoma & $11(2.2)$ \\
Size $<10$ mm with HGD & $1(0.2)$ \\
Size $\geq 10$ mm with LGD & $10(2.0)$ \\
Villous adenoma & $14(2.7)$ \\
Tubulovillous adenoma & $115(22.6)$ \\
With LGD & $107(21.0)$ \\
With HGD & $8(1.6)$ \\
Serrated adenoma & \\
Size $\geq 10$ mm with LGD & $2(0.4)$ \\
Total & $509(100)$ \\
\hline
\end{tabular}

LGD, low-grade dysplasia; HGD, high-grade dysplasia.

Table IV. Histopathological features of 509 polyps according to the patients' age.

\begin{tabular}{lccc}
\hline \multicolumn{3}{c}{ Patient age } & \\
\cline { 2 - 3 } & $\begin{array}{c}\text { 65-74 years } \\
\text { Histopathology }\end{array}$ & $\begin{array}{c}\geq 75 \text { years } \\
\mathrm{N}(\%)\end{array}$ & P-value \\
\hline NAPs & $196(38.5)$ & $67(13.2)$ & $>0.05$ \\
APs & $187(36.7)$ & $59(11.6)$ & \\
NAAs & $91(17.8)$ & $13(2.6)$ & $<0.05$ \\
AAs & $96(18.9)$ & $46(9.0)$ & \\
\hline
\end{tabular}

NAPs, non-adenomatous polyps; NAAs, non-advanced adenomas; AAs, advanced adenomas.

the sigmoid colon, although there was also a significant number of colon polyps and adenomas lying proximal to the splenic flexure. Flexible sigmoidoscopy is recommended as a possible alternative to colonoscopy (20), in which the distal 40-60 cm of the colon (up to the splenic flexure) may be inspected. It is anticipated that examination of the colon limited to the splenic flexure would have 'missed' $34 \%$ of the proximal polyps in our subjects. The incidence of adenomatous polyps in the proximal colon, as well as AAs, has increased in the last few years (16). In addition, Patel et al (18) reported that there 

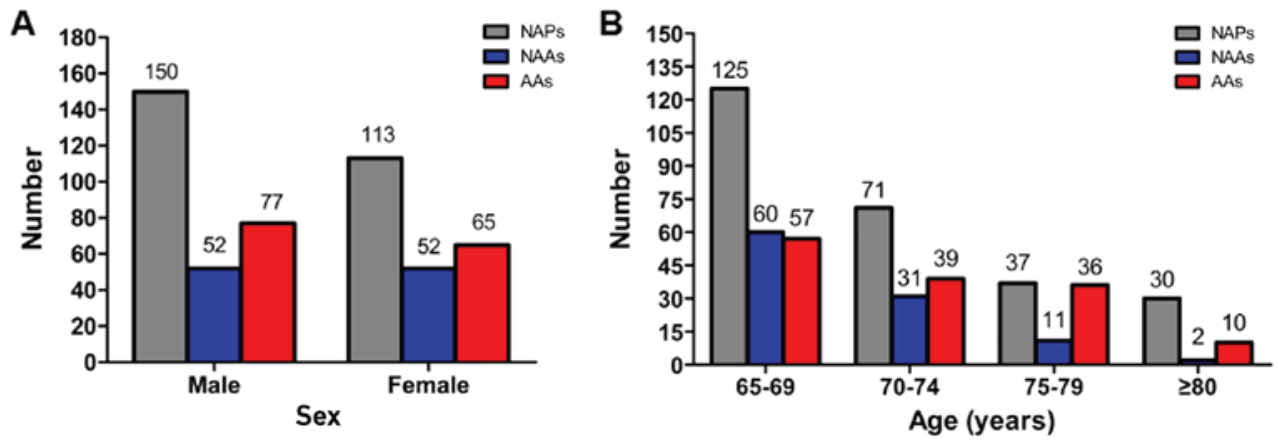

Figure 2. Bar diagram showing the frequency of resected polyps by sex and age. (A) Frequency of colorectal polyps according to the patient's sex. (B) Frequency of colorectal polyps according to the patient age. NAPs, non-adenomatous polyps; NAAs, non-advanced adenomas; AAs, advanced adenomas.
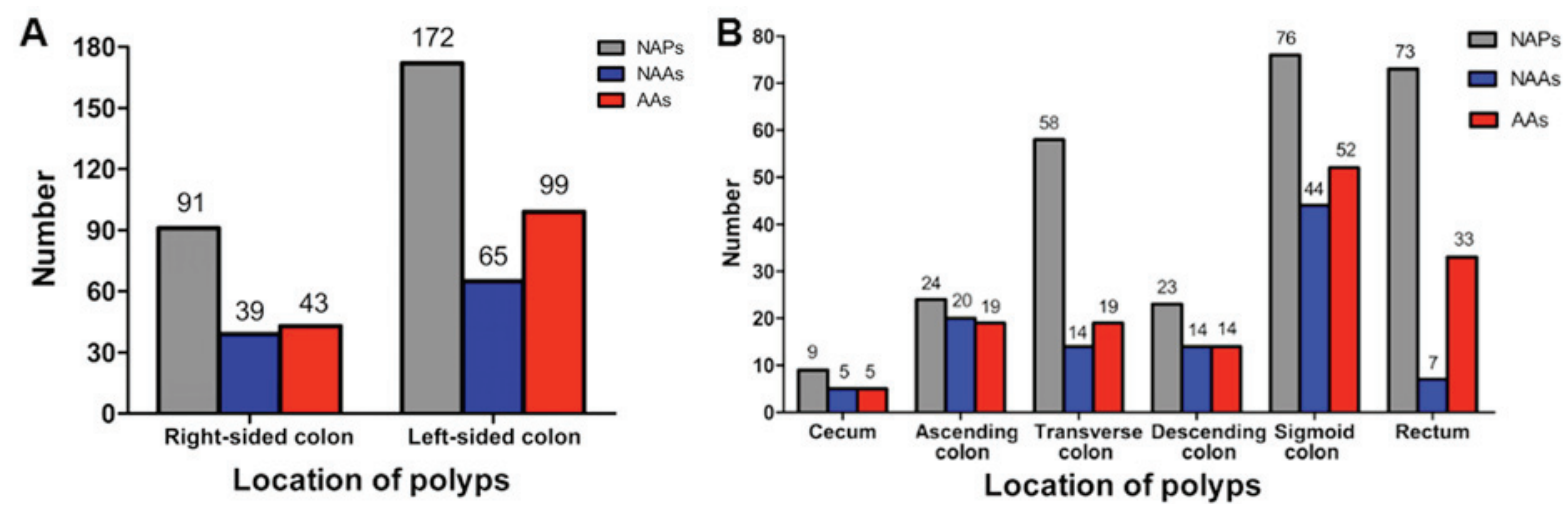

Figure 3. Bar diagram showing the frequency of resected polyps according to their location. (A) Frequency of colorectal polyps in the right-sided and left-sided colon. (B) Frequency of colorectal polyps by anatomical distribution. NAPs, non-adenomatous polyps; NAAs, non-advanced adenomas; AAs, advanced adenomas.
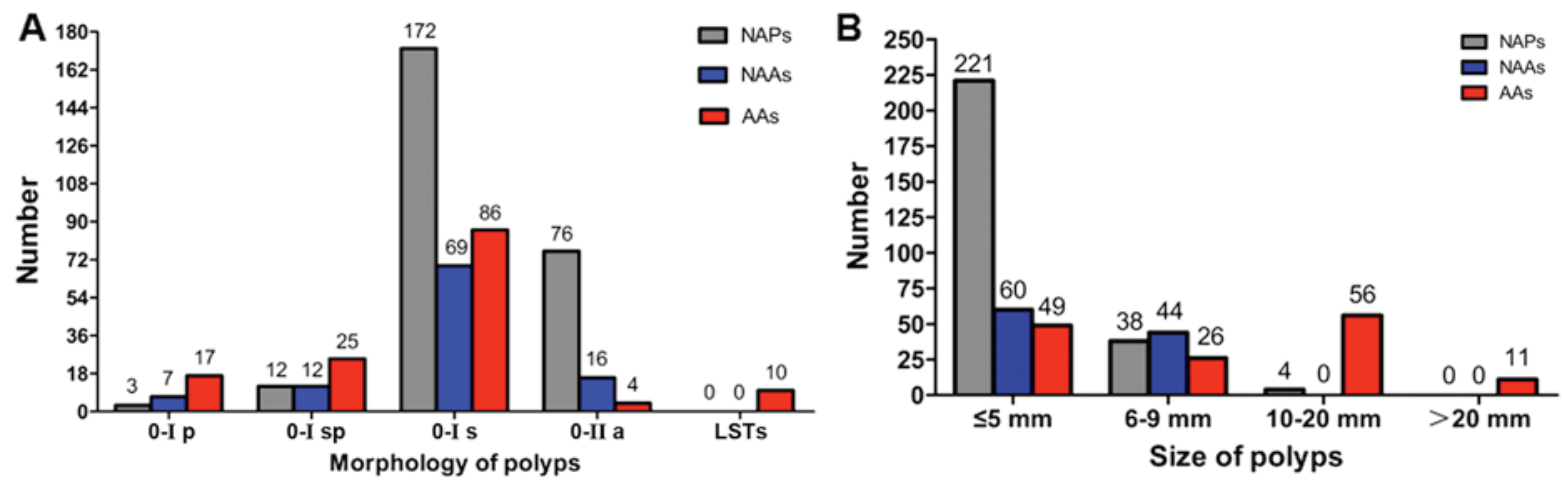

Figure 4. Bar diagram showing the frequency of resected polyps by morphology and size. (A) Frequency of colorectal polyps according to morphological appearance. (B) Frequency of colorectal polyps according to size. NAPs, non-adenomatous polyps; NAAs, non-advanced adenomas; AAs, advanced adenomas.

was an increased right-sided prevalence of adenoma or carcinoma with age. It is clear that evaluation of the whole bowel is particularly important in older patients. However, during daily practice, increasing adverse complications, poorer bowel preparation and more incomplete examinations are observed in older patients undergoing colonoscopy for diagnostic, screening and surveillance purposes (21). In this case, the colonoscopy test for the elderly should be addressed to the whole colon, in preference to methods that evaluate only a part of the colon according to specific factors, such as an elderly patient's comorbid medical conditions, cognitive ability and mobility.
In the present study, sessile type (0-Is) appeared the most frequently for the three different histological features of polyps. No flat and depressed lesions (0-IIb and 0 -IIc) were identified in the present study. The possible reasons for this were poorer bowel preparation, and a less frequent use of dye-chromoendoscopy, such as indigo carmine, or electronic chromoendoscopy, such as the i-Scan procedure (22-24).

Diminutive (1-5 $\mathrm{mm}$ in size) and small (6-9 $\mathrm{mm}$ in size) colorectal polyps represent the majority of polyps that are identifiable during colonoscopy $(25,26)$. A study from Taiwan revealed that $1.3 \%$ of the diminutive polyps had an advanced histology (25). Chaput et al (27) demonstrated an advanced 
Table V. Histopathological features of the 509 polyps according to polyp size.

\begin{tabular}{|c|c|c|c|c|c|c|}
\hline \multirow[b]{2}{*}{ Histopathology } & \multicolumn{2}{|c|}{ Polyp size $(\mathrm{N}, \%)^{\mathrm{a}}$} & \multirow[b]{2}{*}{ P-value } & \multicolumn{2}{|c|}{ Polyp size $(\mathrm{N}, \%)^{\mathrm{b}}$} & \multirow[b]{2}{*}{ P-value } \\
\hline & $0-9 \mathrm{~mm}$ & $\geq 10 \mathrm{~mm}$ & & $0-5 \mathrm{~mm}$ & $\geq 6 \mathrm{~mm}$ & \\
\hline NAPs & $259(50.9)$ & $4(0.8)$ & $<0.0001$ & $221(43.4)$ & $42(8.3)$ & $<0.0001$ \\
\hline APs & $179(35.1)$ & $67(13.2)$ & & $109(21.4)$ & 137 (26.9) & \\
\hline NAAs & $104(20.4)$ & $0(0)$ & $<0.0001$ & $60(11.8)$ & $44(8.6)$ & $<0.0001$ \\
\hline AAs & 75 (14.7) & $67(13.2)$ & & $49(9.6)$ & 93 (18.3) & \\
\hline
\end{tabular}

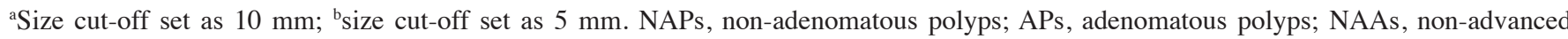
adenomas; AAs, advanced adenomas.

histology in $4.7 \%$ of the diminutive, and $35.2 \%$ of the small polyps, mainly due to presence of a villous component (27). Shapiro et al (28) determined that $4.1 \%$ of the diminutive polyps contained a villous component, and the rate of advanced histology for small polyps was $>15 \%$ (28). In a systematic review by Hassan et al (29), AAs were identified in $4.6 \%$ of diminutive polyps, $7.9 \%$ of small polyps, and $12.5 \%$ of sub-centimetre $(<10 \mathrm{~mm})$ polyps. The observations in the present study revealed that $14.8 \%$ of the diminutive polyps, $24.1 \%$ of the small polyps, and $17.1 \%$ (75/438) of sub-centimetre polyps had an advanced histology, findings that were similar to those previously reported by Tsai et al (30). In that study, which included patients aged 40-89 years, the prevalence of AAs was $10 \%$ in polyps $\leq 5 \mathrm{~mm}$, and $27 \%$ in polyps $6-9 \mathrm{~mm}$ in size (30). The prevalence of an advanced histology in diminutive and small colorectal polyps may vary widely in different studies, and it was suspected by the present authors that the contributing factors would possibly include sample size, the demographics of the screened population, the geographic environment, and dietary habits. In the present study, it was important to note that an increasing polyp size was associated with an increased likelihood of adenoma and advanced histology when the size cut-off for polyps was set at $5 \mathrm{~mm}$ or $10 \mathrm{~mm}$. Therefore, one may conclude that diminutive and small colorectal polyps should not be ignored in older people, and for patients with multiple medical comorbidities, a failure to remove those polyps may place the elderly at risk of progression to advanced lesions and CRC.

A histopathological examination is considered as a gold standard for polyp characterization, and it is essential to recommend a surveillance interval following colonoscopy screening and polypectomy (31). However, the requirement for a post-polypectomy histological assessment leads to a substantial exploitation of medical and economic resources (32). In recent years, a 'resect and discard' strategy based on the findings of image-enhanced endoscopy (e.g., high-definition endoscopy, magnifying endoscopy and chromoendoscopy) for diminutive colorectal polyps has been proposed to save both the time and cost of histopathology (33-36). However, there are several barriers to applying this strategy in the clinical practice of the present authors. First, as the cost for a pathology examination (\$31 per specimen) is relatively inexpensive in Wuhan, according to the regulation of Medicare payment system, there would be no substantial economic benefit compared with
Europe and America. Secondly, current medical legal regulation in China does not allow such management in clinical practice. The standard of medical care remains to submit resected polyps for pathological assessment according to the corresponding expert consensus (37). Thirdly, high-definition endoscopy, magnifying endoscopy, dye-chromoendoscopy and electronic chromoendoscopy [e.g., narrow band imaging (NBI) and i-Scan] have not been used routinely in the clinical practice of the present authors. Considering the development and widespread use of available modern image-enhanced endoscopy, it is anticipated that the 'resect and discard' strategy may be used only by our endoscopists trained with an appropriate diagnostic method in the near future.

There are certain limitations associated with the present study. First, since a single-center retrospective study was performed, as the study subjects did not include adequate numbers of patients from other regions, any generalization of the results was limited by the small sample size and certain bias. The effect of possible confounding factors, such as geographic distribution, diet, physical activity, socioeconomic status and comorbid medical conditions, should be considered. In addition, image-enhanced endoscopy (e.g. high-definition colonoscopy, dye-chromoendoscopy and electronic chromoendoscopy) might have markedly increased the detection of small and flat polyps (22-24); small or flat lesions may occasionally also have been missed due to insufficient technical imaging methods in the present study. Therefore, the study requires replication in other centers, and with multiple technical imaging methods by experienced users.

In conclusion, the present study has revealed that a significant number of colorectal polyps lie proximal to the splenic flexure. Therefore, an evaluation of the whole bowel is particularly important in colonoscopy for the elderly. In addition, since polyp size was associated with the presence of adenoma and an advanced component, the present authors consider that diminutive and small colorectal polyps should not be ignored in elderly patients, in order to decrease the prevalence of advanced lesions and CRC.

\section{Acknowledgments}

The present study was supported by a grant from the Research Funding for Health and Family Planning Commission of Wuhan Municipality (grant no. WX16D38). 


\section{References}

1. World Health Organization International Agency for Research on Cancer: GLOBOCAN 2012: Estimated Cancer Incidence, Mortality and Prevalence Worldwide in 2012. http://www-dep. iarc.fr/. Accessed August 10, 2014.

2. Yazdizadeh B, Jarrahi AM, Mortazavi H, Mohagheghi MA, Tahmasebi S and Nahvijo A: Time trends in the occurrence of major GI cancers in Iran. Asian Pac J Cancer Prev 6: 130-134, 2005.

3. Khuhaprema T and Srivatanakul P: Colon and rectum cancer in Thailand: An overview. Jpn J Clin Oncol 38: 237-243, 2008.

4. Dai Z, Zheng RS, Zou XN, Zhang SW, Zeng HM, Li N and Chen WQ: Analysis and prediction of colorectal cancer incidence trend in China. Zhonghua Yu Fang Yi Xue Za Zhi 46: 598-603, 2012 (In Chinese)

5. Leslie A, Carey FA, Pratt NR and Steele RJ: The colorectal adenoma-carcinoma sequence. Br J Surg 89: 845-860, 2002.

6. Neugut AI, Jacobson JS and De Vivo I: Epidemiology of colorectal adenomatous polyps. Cancer Epidemiol Biomarkers Prev 2: 159-176, 1993

7. Heitman SJ, Ronksley PE, Hilsden RJ, Manns BJ, Rostom A and Hemmelgarn BR: Prevalence of adenomas and colorectal cancer in average risk individuals: A systematic review and meta-analysis. Clin Gastroenterol Hepatol 7: 1272-1278, 2009.

8. Strul H, Kariv R, Leshno M, Halak A, Jakubowicz M, Santo M, Umansky M, Shirin H, Degani Y, Revivo M, et al: The prevalence rate and anatomic location of colorectal adenoma and cancer detected by colonoscopy in average-risk individuals aged 40-80 years. Am J Gastroenterol 101: 255-262, 2006.

9. Short MW, Layton MC, Teer BN and Domagalski JE: Colorectal cancer screening and surveillance. Am Fam Physician 91: 93-100, 2015

10. Aronchick CA, Lipshutz WH, Wright SH, Dufrayne F and Bergman G: A novel tableted purgative for colonoscopic preparation: Efficacy and safety comparisons with colyte and fleet phospho-soda. Gastrointest Endosc 52: 346-352, 2000.

11. Hong SN, Kim JH, Choe WH, Han HS, Sung IK, Park HS and Shim CS: The prevalence and risk of colorectal neoplasm in asymptomatic average-risk screenees aged 40 to 49 years of age. Gastrointest Endosc 72: 480-489, 2010.

12. The Paris endoscopic classification of superficial neoplastic lesions: Esophagus, stomach, and colon: November 30 to December 1, 2002. Gastrointest Endosc 58 (6 Suppl): S3-S43, 2003.

13. Fong TV, Chuah SK, Chiou SS, Chiu KW, Hsu CC, Chiu YC, Wu KL, Chou YP, Ong GY and Changchien CS: Correlation of the morphology and size of colonic polyps with their histology. Chang Gung Med J 26: 339-343, 2003.

14. Pullens HJ, Joosten M, Siersema PD and Brink MA: Open-access flexible sigmoidoscopy frequently leads to additional colonoscopy in symptomatic patients over 50 years. J Gastrointestin Liver Dis 23: 153-159, 2014.

15. Yang MH, Rampal S, Sung J, Choi YH, Son HJ, Lee JH, Kim YH, Chang DK, Rhee PL, Rhee JC, et al: The prevalence of colorectal adenomas in asymptomatic Korean men and women. Cancer Epidemiol Biomarkers Prev 23: 499-507, 2014.

16. de Oliveira AM, Anapaz V, Lourenço L, Graça Rodrigues C, Folgado Alberto S, Martins A, Ramos de Deus J and Reis J: Is there a proximal shift in the distribution of colorectal adenomas? United European Gastroenterol J 3: 353-357, 2015.

17. Yamaji Y, Mitsushima T, Ikuma H, Watabe H, Okamoto M, Kawabe T, Wada R, Doi $\mathrm{H}$ and Omata $\mathrm{M}$ : Incidence and recurrence rates of colorectal adenomas estimated by annually repeated colonoscopies on asymptomatic Japanese. Gut 53: $568-572,2004$

18. Patel K and Hoffman NE: The anatomical distribution of colorectal polyps at colonoscopy. J Clin Gastroenterol 33: 222-225, 2001

19. Zare-Mirzaie A, Abolhasani M and Aryamanesh A: Left sided colorectal adenomatous polyps have more risk for high grade dysplasia. Acta Med Iran 51: 172-177, 2013.

20. Levin B, Lieberman DA, McFarland B, Smith RA, Brooks D, Andrews KS, Dash C, Giardiello FM, Glick S, Levin TR, et al: Screening and surveillance for the early detection of colorectal cancer and adenomatous polyps, 2008: A joint guideline from the American cancer society, the US multi-society task force on colorectal cancer, and the american college of radiology. CA Cancer J Clin 58: 130-160, 2008.
21. Day LW and Velayos F: Colorectal cancer screening and surveillance in the elderly: Updates and controversies. Gut Liver 9: 143-151, 2015.

22. Trecca A, Gaj F, Di Lorenzo GP, Ricciardi MR, Silano M, Bella A and Sperone M: Improved detection of colorectal neoplasms with selective use of chromoendoscopy in 2005 consecutive patients. Tech Coloproctol 10: 339-344, 2006.

23. Park SY, Lee SK, Kim BC, Han J, Kim JH, Cheon JH, Kim TI and Kim WH: Efficacy of chromoendoscopy with indigocarmine for the detection of ascending colon and cecum lesions. Scand J Gastroenterol 43: 878-885, 2008.

24. Testoni PA, Notaristefano C, Vailati C, Di Leo M and Viale E: High-definition colonoscopy with i-Scan: Better diagnosis for small polyps and flat adenomas. World J Gastroenterol 18: 5231-5239, 2012.

25. Chiu HM, Chang LC, Shun CT, Wu MS and Wang HP: Current management of diminutive colorectal polyps in Taiwan. Dig Endosc 26 (Suppl 2): S64-S67, 2014

26. Matsuda T, Kawano H, Hisabe T, Ikematsu H, Kobayashi N, Mizuno K, Oka S, Takeuchi Y, Tamai N, Uraoka T, et al: Current status and future perspectives of endoscopic diagnosis and treatment of diminutive colorectal polyps. Dig Endosc 26 (Suppl 2): S104-S108, 2014

27. Chaput U, Alberto SF, Terris B, Beuvon F, Audureau E, Coriat R, Roche H, Gaudric M, Prat F and Chaussade S: Risk factors for advanced adenomas amongst small and diminutive colorectal polyps: A prospective monocenter study. Dig Liver Dis 43: 609-612, 2011.

28. Shapiro R, Ben-Horin S, Bar-Meir S and Avidan B: The risk of advanced histology in small-sized colonic polyps: Are non-invasive colonic imaging modalities good enough? Int J Colorectal Dis 27: 1071-1075, 2012 .

29. Hassan C, Pickhardt PJ, Kim DH, Di Giulio E, Zullo A, Laghi A, Repici A, Iafrate F, Osborn J and Annibale B: Systematic review: Distribution of advanced neoplasia according to polyp size at screening colonoscopy. Aliment Pharmacol Ther 31: 210-217, 2010.

30. Tsai FC and Strum WB: Prevalence of advanced adenomas in small and diminutive colon polyps using direct measurement of size. Dig Dis Sci 56: 2384-2388, 2011.

31. Lieberman DA, Rex DK, Winawer SJ, Giardiello FM, Johnson DA and Levin TR; United States Multi-Society Task Force on Colorectal Cancer: Guidelines for colonoscopy surveillance after screening and polypectomy: A consensus update by the US multi-society task force on colorectal cancer. Gastroenterology 143: 844-857, 2012.

32. Hassan C, Repici A, Zullo A and Sharma P: New paradigms for colonoscopic management of diminutive colorectal polyps: Predict, resect, and discard or do not resect? Clin Endosc 46: 130-137, 2013.

33. Ignjatovic A, East JE, Suzuki N, Vance M, Guenther T and Saunders BP: Optical diagnosis of small colorectal polyps at routine colonoscopy (Detect InSpect ChAracterise Resect and Discard; DISCARD trial): A prospective cohort study. Lancet Oncol 10: 1171-1178, 2009.

34. Hassan C, Pickhardt PJ and Rex DK: A resect and discard strategy would improve cost-effectiveness of colorectal cancer screening. Clin Gastroenterol Hepatol 8: 865-869, 2010.

35. McGill SK, Evangelou E, Ioannidis JP, Soetikno RM and Kaltenbach T: Narrow band imaging to differentiate neoplastic and non-neoplastic colorectal polyps in real time: A meta analysis of diagnostic operating characteristics. Gut 62: 1704-1713, 2013.

36. Takeuchi Y, Hanafusa M, Kanzaki H, Ohta T and Hanaoka N: Proposal of a new 'resect and discard' strategy using magnifying narrow band imaging: Pilot study of diagnostic accuracy. Dig Endosc 26 (Suppl 2): S90-S97, 2014.

37. Endoscopic Diagnosis and Treatment Group of Early Digestive Cancer, Chinese Society of Digestive Endoscopy; Gastrointestinal tumor group, Chinese Society of Gastroenterology and Intestinal Study group, Chinese Society of Digestive Endoscopy: Chinese consensus: screening, diagnosis and treatment of early colorectal cancer and precancerous lesions (2014, Chongqing). Chin J Dig Endosc 2: 69-85, 2015 (In Chinese). 